\title{
FUNGICIDAS FOLIARES E A DOENÇA FERRUGEM ASIÁTICA NA PRODUÇÃO E NA QUALIDADE DE SEMENTES DE SOJA ${ }^{1}$
}

\author{
TAIS LEITE FERREIRA PINTO², SILVIO MOURE CICERO², \\ JOSÉ DE BARROS FRANÇA NETO ${ }^{4}$, DURVAL DOURADO NETO ${ }^{3}$, VICTOR AUGUSTO FORTI ${ }^{5}$
}

\begin{abstract}
RESUMO - Condições climáticas desfavoráveis, durante o período final de maturação da soja, têm ocasionado problemas na qualidade das sementes, o que pode resultar no aparecimento de sementes esverdeadas. No presente trabalho objetivou-se avaliar a influência da aplicação foliar de fungicidas e da doença ferrugem asiática na produção e na qualidade de sementes, com destaque para a ocorrência de sementes esverdeadas em soja. Os tratamentos foram constituídos pela testemunha e aplicações dos fungicidas flutriafol + tiofanato metílico, pyraclostrobina + epoxiconazol e metconazol, sendo os produtos aplicados nos estádios fenológicos $\mathrm{R}_{2}$ e $\mathrm{R}_{5.1}$, individualmente e, também, em aplicações combinadas. Os experimentos foram conduzidos em campo, em Londrina-PR, durante os anos agrícolas de 2007/08 e 2008/09. Foram realizadas as seguintes avaliações de campo: severidade da doença ferrugem asiática, por meio de escala diagramática, produtividade, massa de mil sementes e porcentagem de sementes esverdeadas, avaliadas visualmente. A qualidade das sementes foi avaliada por meio dos testes de germinação, tetrazólio, envelhecimento acelerado e condutividade elétrica, imediatamente após a colheita e após 6 meses de armazenamento, e pelo teste de fluorescência de clorofila nas sementes do segundo ano agrícola. O delineamento experimental utilizado foi em blocos ao acaso, sendo as médias comparadas pelo teste de Tukey, aos $5 \%$ de probabilidade. Os fungicidas foliares, que controlam de forma eficiente a doença ferrugem asiática, não interferem na produção, na qualidade das sementes e na ocorrência de sementes esverdeadas. Em condições climáticas favoráveis à maturação das sementes, a alta severidade da doença ferrugem asiática interfere na produtividade, mas não influencia no seu potencial fisiológico. A ferrugem asiática associada às condições climáticas desfavoráveis na fase final de maturação proporciona a ocorrência de sementes esverdeadas que compromete o vigor das sementes após o armazenamento.
\end{abstract}

Termos de indexação: sementes esverdeadas; qualidade de sementes; Glycine max ( L.) Merrill; Phakopsora pachyrhizi Sydow.

\section{FOLIAGE FUNGICIDES AND ASIATIC RUST DISEASE ON THE PRODUCTION AND QUALITY OF SOYBEAN SEEDS}

\begin{abstract}
Unfavorable weather conditions during late soybean maturation have caused problems in seed quality due to "forced maturation" or premature plant death, which can result in green seeds. This study aimed to evaluate the effect of fungicides and rust disease on soybean seed yield and quality, focusing on the occurrence of green seeds. The treatments included a control
\end{abstract}

\footnotetext{
${ }^{1}$ Submetido em 02/09/10. Aceito para a publicação em 06/04/11. Parte da Tese de Doutorado da primeira autora, USP/ESALQ.

${ }^{2}$ Eng. Agr., Doutora em Ciências, USP/ESALQ, e-mail: tais_leite@ yahoo.com

${ }^{3}$ Eng. Agr., Dr., Professor Titular, Departamento de Produção Vegetal, USP/ESALQ, Caixa postal 09, CEP 13.418-900, Piracicaba, bolsista de
}

produtividade em pesquisa do CNPq, e-mail: smcicero@esalq.usp.br, dourado@esalq.usp.br

${ }^{4}$ Eng. Agr., Ph.D., Pesquisador, Embrapa Soja, e-mail: jbfranca@cnpso. embrapa.br

${ }^{5}$ Eng. Agr., Doutorando do Programa de Pós-Graduação em Fitotecnia, Departamento de Produção Vegetal, USP/ESALQ, e-mail: vaforti@ esalq.usp.br 
and fungicide applications of flutriafol + thiophanate- methyl, pyraclostrobin + epoxiconazole and metconazole, in the $\mathrm{R}_{2}$ and $\mathrm{R}_{5.1}$ growth stages, individually and also in combined applications. The experiments were carried out in the field at Londrina-PR, during the 2007/08 and 2008/09 crop cycles with the Coodetec 206 cultivar. The following evaluations were made: rust disease severity using a diagrammatic scale, productivity, seed weight and visual assessment of the percentage of green seed. Seed quality was evaluated from germination, tetrazolium, accelerated aging and electrical conductivity tests. Analyses were performed immediately after harvest and after six months of storage. The fluorescence chlorophyll test was carried out in the second crop seeds. The experimental design was randomized blocks with seven treatments and four blocks for each crop. Means were compared by the Tukey test at 5\% probability. The fungicide, that efficiently controlled soybean rust did not affect production and seed quality or the occurrence of green seed. Under favorable weather conditions for seed maturation, the severity of soybean Asiatic rust interferes with production but does not influence seed physiological potential. Soybean rust associated with unfavorable weather conditions during the final stage of maturation results in green soybean seeds that reduce vigor after storage.

Keywords: green seeds; seed quality; Glycine max ( L.) Merrill; Phakopsora pachyrhizi Sydow.

\section{INTRODUÇÃO}

As safras 2004/2005, 2005/2006 e 2008/2009 de soja no Brasil, foram caracterizadas pela ocorrência de secas e temperaturas acima da média histórica em diversas regiões produtoras dos Estados do Rio Grande do Sul, Santa Catarina, Paraná, São Paulo, Mato Grosso do Sul, Mato Grosso e Goiás, ocasionando acentuadas perdas de produtividade e ocorrência de sementes e grãos esverdeados de soja. Isso ocorre devido à degradação parcial da clorofila na semente durante a fase final da maturação e tem causado preocupação aos produtores brasileiros, pois este fenômeno acarreta prejuízos tanto na indústria de óleos comestíveis como para a produção de sementes.

A ocorrência de sementes esverdeadas tem propiciado descarte de muitos lotes devido ao decréscimo da qualidade, pois afeta, significativamente, o estabelecimento de estande, uma vez que estas sementes têm potencial para apresentar problemas na emergência, podendo resultar em perdas de produtividade.

A ferrugem asiática, causada por Phakopsora pachyrhizi Sydow, foi identificada pela primeira vez no Brasil no final da safra 2000/01, por meio de dois trabalhos de detecção de doença no Paraná, realizados por Jaccound Filho et al. (2001) e Yorinori et al. (2002).

Os sintomas iniciais da doença consistem de pequenas lesões foliares, de coloração castanha a marrom-escuro. $\mathrm{Na}$ face inferior da folha pode-se observar soros urediniais liberando os urediniósporos. As lesões tendem para o formato angular entre 2 e $5 \mathrm{~mm}$ de diâmetro e, embora não seja comum, pode ocorrer nos pecíolos, vagens e hastes (Sinclair e Hartman, 1999). Plantas severamente infectadas apresentam desfolha precoce, comprometendo a formação e a massa final dos grãos (Yang et al., 1991). A doença pode também interferir na degradação da clorofila nas sementes, proporcionando a ocorrência de sementes esverdeadas. Os danos causados pela ferrugem asiática em outros países produtores, onde a doença ocorre há mais tempo, são acentuados, podendo causar perdas de até $80 \%$ na produtividade (Sinclair e Hartman, 1999).

Sob circunstâncias normais, durante a maturação das sementes, a enzima clorofilase degrada a clorofila presente nas sementes de soja, proporcionando o aparecimento da coloração amarela da semente, que é um dos indicativos de que a mesma atingiu a maturidade fisiológica. Porém, se durante os últimos estádios de maturação da semente as condições de tempo forem excessivamente quente e seco, a secagem das sementes ocorre de forma rápida, podendo haver a interrupção da atividade da enzima antes que toda a clorofila tenha sido degradada (Bohner, 2003). O grau de coloração verde dependerá do estádio de desenvolvimento da planta quando ocorreu a situação de estresses que causou sua morte prematura. Se ocorrer na fase final de enchimento 
de grãos, a coloração esverdeada estará concentrada no tegumento e poderá diminuir durante o armazenamento. Se ocorrer no início ou no meio desta fase, o pigmento estará distribuído por todo o grão e não será degradado, mesmo com um longo período de armazenamento (Wiebold, 2000).

No presente trabalho objetivou-se avaliar o efeito de diferentes fungicidas no controle da ferrugem asiática e seu efeito na produção e na qualidade de sementes de soja, com destaque para a ocorrência de sementes esverdeadas.

\section{MATERIAL E MÉTODOS}

O experimento em campo foi conduzido no município de Londrina, PR (latitude $23^{\circ} 18^{\prime} 37^{\prime}$ 'sul, longitude $51^{\circ} 09^{\prime} 46^{\prime}$ ' oeste), nas safras 2007/08 e 2008/09 sendo utilizada a cultivar CD 206.

Foram constituídos sete tratamentos: 1) testemunha - sem aplicação de fungicida; 2) Flutriafol + tiofanato metílico (triazol), na dose de $0,5 \mathrm{~L}$ do produto comercial (p.c.). ha-1 aplicado em $\mathrm{R}_{2}$ e $\mathrm{R}_{5.1}$; 3) tebuconazol (triazol), na dose de $0,5 \mathrm{~L}$ de produto comercial (p.c.).ha ${ }^{-1}$, aplicado em $\mathrm{R}_{2}$ e $\mathrm{R}_{5.1}$; 4) pyraclostrobin + epoxiconazol (triazol + estrobilurina) na dose de $0,5 \mathrm{~L}$ de p.c.ha ${ }^{-1}$, aplicado em $\mathrm{R}_{2}$ $\mathrm{e}_{5.1}$; 5) metconazol (triazol) na dose de $0,6 \mathrm{~L}$ de p.c.ha ${ }^{-1}$, aplicado em $\mathrm{R}_{2}$ e $\mathrm{R}_{5.1}$; 6) metconazol, na dose de $0,6 \mathrm{~L}$ de p.c.ha ${ }^{-1}$, aplicado em $\mathrm{R}_{2}$ e pyraclostrobin + epoxiconazol, na dose de $0,5 \mathrm{~L}$ de p.c.ha ${ }^{-1}$, em R5.1; 7) pyraclostrobin + epoxiconazol, na dose de $0,5 \mathrm{~L}$ de p.c.ha ${ }^{-1}$, aplicado em $\mathrm{R}_{2}$ e metconazol, na dose de $0,6 \mathrm{~L}$ de p.c.ha ${ }^{-1}$, aplicado em $R_{5.1}$.

\section{Condução dos experimentos}

As semeaduras foram realizadas nos dias 9 de novembro de 2007 e 18 de novembro de 2008, em Londrina-PR. Os dados de precipitação pluvial e de temperaturas máxima e mínima diárias foram coletados em postos meteorológicos, próximos às áreas experimentais, a partir da antese (Figuras 1 e 2).

As pulverizações com fungicidas nas parcelas experimentais foram realizadas por meio de pulverizador costal, composto por cilindro de $\mathrm{CO}_{2}$. Para o controle da deriva, foi utilizada uma lona plástica esticada nas laterais de cada parcela pulverizada.

Cada parcela experimental foi constituída por cinco linhas de $6 \mathrm{~m}$, espaçadas a $0,45 \mathrm{~m}$ entre si, com área total de $13,5 \mathrm{~m}^{2}$. A área útil de cada parcela foi de $5,4 \mathrm{~m}^{2}$, constituindo-se na utilização das três linhas centrais, sendo eliminados $0,5 \mathrm{~m}$ de cada extremidade. As colheitas foram realizadas nos dias 15 de março de 2008 e 18 de março de 2009.

\section{Avaliação da incidência de ferrugem asiática}

A avaliação da severidade da doença foi realizada com auxílio de escala diagramática, estimando a severidade nos três terços da planta (inferior, médio e superior), de acordo com as normas para avaliação e recomendação de fungicidas para a cultura da soja (Embrapa Soja, 2008).

\section{Avaliação da produção de sementes}

A colheita foi efetuada no estádio $\mathrm{R}_{8}$ (Fehr et al. (1971). Posteriormente, foi realizada a trilha e limpeza do material. $\mathrm{Na}$ sequência, foi determinada a massa das sementes colhidas em cada unidade experimental e a produtividade (kg. ha ${ }^{-1}$ ), considerando o teor água de 13\% (base úmida).

\section{Porcentagem de sementes esverdeadas}

Cem sementes de cada repetição foram seccionadas de forma a visualizar possíveis tons de verde no seu interior. Os resultados foram expressos em porcentagem.

\section{Avaliação da qualidade das sementes}

Os testes de avaliação da qualidade foram realizados imediatamente após a colheita e após sete meses de armazenamento.

Teor de água: foi determinado pelo método padrão de estufa a $105{ }^{\circ} \mathrm{C} \pm 3{ }^{\circ} \mathrm{C}$, por 24 horas (Brasil, 2009). Os resultados, expressos em percentagem, foram calculados com base na massa de semente úmida $(\mathrm{Bu})$.

Teste de germinação: foi realizado com quatro repetições de 50 sementes por tratamento, semeadas em substrato de papel na forma de rolo, umedecidos com quantidade de água equivalente a 2,5 vezes a massa seca do substrato. Os rolos foram mantidos em germinador previamente regulado à temperatura constante de $25^{\circ} \mathrm{C}$. As avaliações foram realizadas de acordo com Brasil (2009) e os resultados expressos em porcentagem.

Teste de tetrazólio: duas subamostras de cinquenta sementes por repetição de cada tratamento foram acondicionadas em substrato de papel do tipo germitest umedecido, com quantidade de água equivalente a 2,5 vezes a sua massa, durante 16 horas, aos $25^{\circ} \mathrm{C}$. Posteriormente, as sementes foram colocadas em solução com concentração de $0,075 \%$ de 2,3,5-trifenil-cloreto de tetrazólio, no escuro, em estufa, com temperatura de $40{ }^{\circ} \mathrm{C}$, por 2 horas. Após esse período, as sementes foram lavadas em água corrente e analisadas, individualmente, quanto à viabilidade e vigor, conforme metodologia descrita por (França Neto et al. 1999).

Teste de envelhecimento acelerado: foram utilizadas quatro repetições por tratamento, com cinquenta sementes 
cada, colocadas em caixas plásticas de germinação, sobre uma tela de aço inox, contendo $40 \mathrm{~mL}$ de água deionizada, sendo estas mantidas em câmara de envelhecimento (BOD) aos $42{ }^{\circ} \mathrm{C}$ e $100 \%$ de umidade relativa do ar (Marcos Filho, 1999). Após 48 horas, as sementes foram colocadas para germinar da mesma maneira descrita para o teste de germinação. A avaliação de plântulas normais foi realizada conforme a recomendação das Regras para Análise de Sementes (Brasil, 2009).

Teste de condutividade elétrica: foi realizado com quatro repetições de cinquenta sementes por tratamento, pesadas com precisão de $0,01 \mathrm{~g}$, colocadas em copos plásticos contendo $75 \mathrm{~mL}$ de água deionizada e mantidas em incubadora (BOD) à temperatura constante de $25^{\circ} \mathrm{C} \pm$ $1{ }^{\circ} \mathrm{C}$, por 24 horas (Vieira e Krzyanowski, 1999). Após esse período, foi efetuada a leitura da condutividade elétrica da solução. Os resultados foram obtidos calculando-se a condutividade elétrica determinada para cada repetição, dividida pela massa das sementes, sendo expressos em $\mu \mathrm{S} . \mathrm{cm}^{-1} \cdot \mathrm{g}^{-1}$.

Teste de fluorescência de clorofila: Mil sementes de cadarepetição, do segundoanoexperimental, correspondente a segunda época de avaliação, foram submetidas ao teste de fluorescência de clorofila (FC), por meio do equipamento "CF Seed Sorter \& Analyser", modelo JS-2001, do "Plant Research International”, Wageningen, Holanda. Optou-se por realizar o teste após o armazenamento, para avaliar a possível influência da clorofila não degradada no potencial fisiológico das sementes próximo à semeadura.

A técnica consiste em um sistema de excitação por laser e detecção da fluorescência de clorofila por meio de um fotodiodo; é um método não destrutivo e automatizado para a determinação da qualidade de sementes, sendo as mesmas avaliadas individualmente. O equipamento é composto por um laser de diodo que emite luz na faixa de comprimento de onda de $670 \mathrm{~nm}$ (Hewlett Packard HLMP -8150), comprimento de absorção de energia pela molécula de clorofila $a$. Uma parte desta energia é absorvida pela semente, enquanto que, a energia excedente é dissipada na forma de radiação, com energia menor do que a incidida e, consequentemente, maior comprimento de onda, que é detectado por um fotodiodo com um filtro óptico de interferência centrado no comprimento de $730 \mathrm{~nm}$, que permite a detecção apenas da fluorescência proveniente da clorofila $a$. Por meio de um software, os valores de FC são registrados, em pA, e construídos histogramas para averiguação da confiabilidade dos resultados.

\section{Análise estatística}

Para cada safra, o delineamento experimental utilizado foi em blocos casualizados, com sete tratamentos e quatro blocos, sendo as avaliações relativas à qualidade fisiológica das sementes realizadas após a colheita e sete meses após o armazenamento das mesmas. Os dados avaliados foram analisados por meio do software SAS (SAS Institute, 2000), comparando as médias por meio do Teste de Tukey, aos $5 \%$ de probabilidade.

\section{RESULTADOS E DISCUSSÃO}

As condições climáticas no ano agrícola 2007/08 (Figura 1) favoreceram o desenvolvimento do fitopatógeno Phakopsora pachyrhizi Sydow (alta ocorrência na testemunha); além da testemunha, foi verificada alta ocorrência da doença no tratamento 2 (fungicida flutriafol + tiofanato metílico, aplicado nos estádios $R_{2}$ e $R_{5.1}$ ), indicando a baixa eficiência deste tratamento no controle da doença (Tabela 1). Segundo Sinclair e Backman (1989), o intervalo de temperatura ótima para a infecção ocorre entre 20 e $25{ }^{\circ} \mathrm{C}$ e está associado à disponibilidade de água livre sobre a superfície da planta, sendo que quanto maior a duração do molhamento foliar, maiores serão as chances de estabelecimento da infecção.

A porcentagem de sementes esverdeadas nessa safra foi baixa para todos os tratamentos, possivelmente devido às condições climáticas adequadas ao pleno desenvolvimento da cultura, isto é, temperaturas amenas e alta umidade relativa do ar (Tabela 1). Segundo Ward et al. (1995), a temperatura tem efeito significativo na taxa de degradação da clorofila nas sementes de canola durante a maturação e Pádua et al (2009) confirmou a importância da temperatura no metabolismo da clorofila em sementes de soja (entre 28 e $32{ }^{\circ} \mathrm{C}$ ) associado ao corte total de irrigação, em experimento conduzido em câmara de crescimento. $\mathrm{O}$ estresse apenas provocado pela ferrugem asiática na planta não interferiu na ocorrência de sementes esverdeadas. Desta forma, a degradação da clorofila nas sementes não foi comprometida pela ocorrência da doença e nem pelo efeito dos fungicidas.

A elevada severidade da doença ferrugem asiática interferiu negativamente no rendimento e massa de sementes, como verificado nos tratamentos 1 e 2, que apresentaram as menores médias. Quanto ao efeito dos fungicidas, observa-se que não houve diferença na produtividade e na massa de mil sementes quando comparados. Swoboda e Pedersen (2009) também não 
observaram incremento na produtividade de soja com a utilização de fungicidas do grupo das estrobilurinas; portanto, não constataram efeitos fisiológicos nas plantas.
Assim, deve haver a interferência de outros fatores, como o climático, que contribui para a expressão dos efeitos fisiológicos da estrobilurina nas plantas.

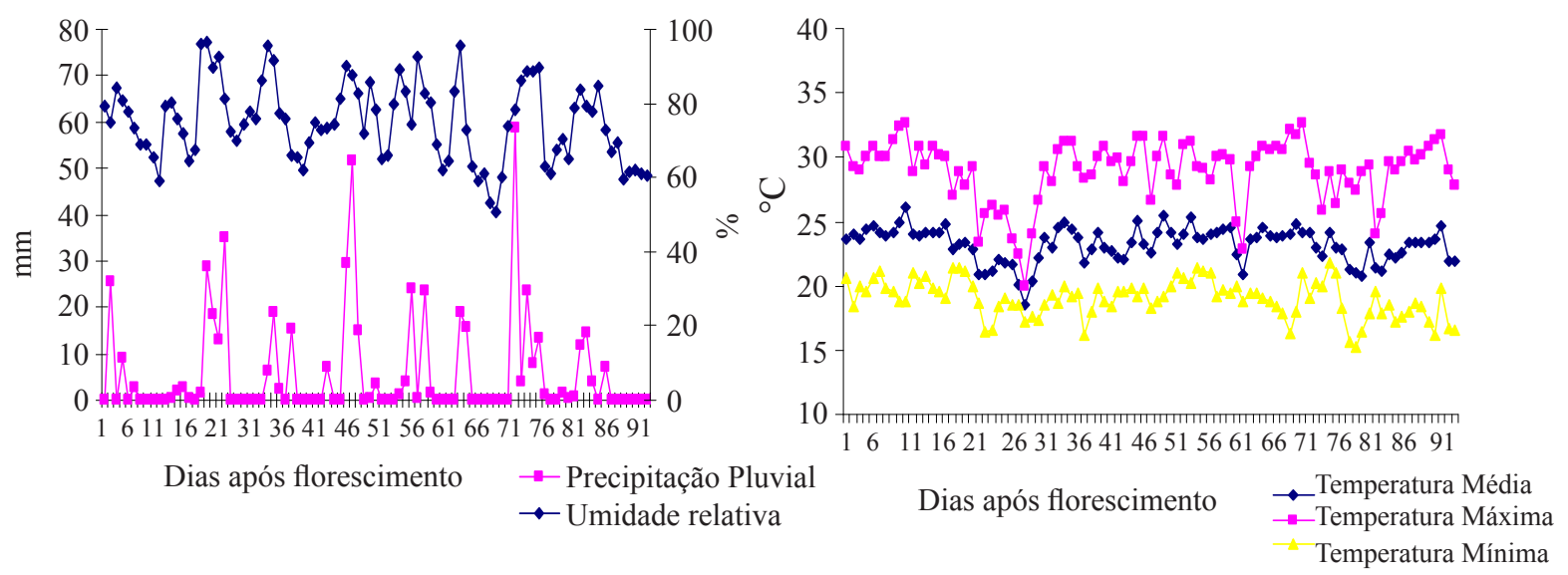

FIGURA 1. Dados meteorológicos de Londrina-PR, coletados do dia 14 de dezembro de 2007 a 15 de março de 2008.

TABELA 1. Médias de severidade de ferrugem asiática (SFA), ocorrência de sementes esverdeadas (OSV), produtividade $(P)$ e massa de mil sementes $\left(M_{1000}\right)$, cultivar CD 206, da safra 2007/2008.

\begin{tabular}{ccccc}
\hline \multirow{2}{*}{$\mathrm{T}$} & SFA & OSV & \multicolumn{1}{c}{$\mathrm{P}$} & $\mathrm{M}_{1000}$ \\
\cline { 2 - 5 } & & $\%$ & $\mathrm{~kg} \cdot \mathrm{ha}^{-1}$ & $\mathrm{~g}$ \\
\hline 1 & $70 \mathrm{a}$ & 1 & $985,2 \mathrm{c}$ & $91,6 \mathrm{c}$ \\
2 & $48 \mathrm{~b}$ & 2 & $1363,5 \mathrm{c}$ & $100,7 \mathrm{bc}$ \\
3 & $10 \mathrm{~cd}$ & 0 & $2248,8 \mathrm{ab}$ & $122,7 \mathrm{ab}$ \\
4 & $9 \mathrm{~cd}$ & 0 & $1911,7 \mathrm{abc}$ & $119,8 \mathrm{ab}$ \\
5 & $9 \mathrm{~cd}$ & 1 & $1946,4 \mathrm{abc}$ & $123,9 \mathrm{ab}$ \\
6 & $4 \mathrm{~d}$ & 1 & $2339,9 \mathrm{ab}$ & $129,3 \mathrm{a}$ \\
7 & $3 \mathrm{~d}$ & 1 & $2856,1 \mathrm{a}$ & $127,7 \mathrm{a}$ \\
\hline $\mathrm{CV}(\%)$ & 52,31 & - & 22,591 & 8,917 \\
\hline
\end{tabular}

Médias seguidas por letras diferentes na coluna diferem entre si pelo teste de Tukey aos 5\% de probabilidade.

$\mathrm{Na}$ primeira época de avaliação do primeiro ano experimental, as sementes apresentaram elevado potencial fisiológico, evidenciado pelos testes de germinação e de vigor, não havendo diferença significativa entre as médias dos tratamentos estudados (Tabela 2), apenas o teste de tetrazólio detectou diferença no vigor, sendo que o tratamento 5 apresentou melhor desempenho, diferindo dos tratamentos 4 e 6 (Tabela 2). Após o armazenamento, os testes de avaliação da qualidade também não detectaram diferenças entre os tratamentos (Tabela 2), porém, as sementes dos tratamentos 2, 3 e 7 apresentaram reduções na germinação que comprometeriam a comercialização das mesmas, por se apresentarem abaixo do padrão mínimo, que é $80 \%$. 
TABELA 2. Resultados de teor de água (TA), germinação (G), envelhecimento acelerado (EA), condutividade elétrica (CE), tetrazólio (TZ) vigor (Vi) e viabilidade (Vb), referentes a primeira e segunda épocas de avaliação, cultivar CD 206, safra 2007/2008.

\begin{tabular}{|c|c|c|c|c|c|c|c|c|c|c|c|c|}
\hline \multirow{4}{*}{$\mathrm{T}$} & \multicolumn{6}{|c|}{ Primeira época de avaliação } & \multicolumn{6}{|c|}{ Segunda época de avaliação } \\
\hline & \multirow{3}{*}{ TA } & \multirow{2}{*}{ G } & \multirow{2}{*}{ EA } & \multirow{2}{*}{$\mathrm{CE}$} & \multicolumn{2}{|c|}{$\mathrm{TZ}$} & \multirow{2}{*}{ TA } & \multirow{2}{*}{ G } & \multirow{2}{*}{ EA } & \multirow{2}{*}{$\mathrm{CE}$} & \multicolumn{2}{|c|}{$\mathrm{TZ}$} \\
\hline & & & & & $\mathrm{Vi}$ & $\mathrm{Vb}$ & & & & & $\mathrm{Vi}$ & $\mathrm{Vb}$ \\
\hline & & $\%$ & & $\mu \mathrm{S} . \mathrm{cm}^{-1} \cdot \mathrm{g}^{-1}$ & & & $\%$ & & & $\mu \mathrm{S} . \mathrm{cm}^{-1} \cdot \mathrm{g}^{-1}$ & & $\%$ \\
\hline 1 & 11,0 & $87 \mathrm{a}$ & $93 \mathrm{a}$ & $70,9 \mathrm{a}$ & $85 \mathrm{ab}$ & $92 \mathrm{a}$ & 9,0 & $83 \mathrm{a}$ & $40 \mathrm{a}$ & 89,0 a & $84 \mathrm{a}$ & $94 \mathrm{a}$ \\
\hline 2 & 10,8 & $82 \mathrm{a}$ & $81 \mathrm{a}$ & 83,6 a & $87 a b$ & $91 \mathrm{a}$ & 9,1 & $76 \mathrm{a}$ & $43 \mathrm{a}$ & $82,7 \mathrm{a}$ & $83 \mathrm{a}$ & $91 \mathrm{a}$ \\
\hline 3 & 10,8 & $88 \mathrm{a}$ & $85 \mathrm{a}$ & $68,2 \mathrm{a}$ & $86 a b$ & $93 \mathrm{a}$ & 9,3 & $78 \mathrm{a}$ & $57 \mathrm{a}$ & $78,4 \mathrm{a}$ & $79 \mathrm{a}$ & $90 \mathrm{a}$ \\
\hline 4 & 10,9 & $89 \mathrm{a}$ & $88 \mathrm{a}$ & $69,8 \mathrm{a}$ & $82 \mathrm{~b}$ & $91 \mathrm{a}$ & 9,1 & $87 \mathrm{a}$ & $60 a$ & $82,3 \mathrm{a}$ & $84 \mathrm{a}$ & $93 \mathrm{a}$ \\
\hline 5 & 11,1 & $84 \mathrm{a}$ & $87 \mathrm{a}$ & 67,6 a & $92 \mathrm{a}$ & $95 a$ & 9,2 & $80 a$ & $62 a$ & $79,4 \mathrm{a}$ & $86 a$ & $94 \mathrm{a}$ \\
\hline 6 & 10,8 & $85 \mathrm{a}$ & $87 \mathrm{a}$ & $64,7 \mathrm{a}$ & $81 \mathrm{~b}$ & $91 \mathrm{a}$ & 9,0 & $80 a$ & $58 \mathrm{a}$ & $82,3 \mathrm{a}$ & $83 a$ & $94 \mathrm{a}$ \\
\hline 7 & 10,8 & $92 \mathrm{a}$ & $81 \mathrm{a}$ & $70,9 \mathrm{a}$ & $86 a b$ & $93 a$ & 9,1 & $76 a$ & $57 \mathrm{a}$ & $81,7 \mathrm{a}$ & $81 \mathrm{a}$ & $90 \mathrm{a}$ \\
\hline $\mathrm{CV}(\%)$ & - & 6,46 & 6,54 & 18,63 & 4,65 & 3,73 & - & 10,14 & 15,64 & 12,81 & 5,46 & 5,16 \\
\hline
\end{tabular}

Médias seguidas por letras diferentes na coluna diferem entre si pelo teste de Tukey aos 5\% de probabilidade.

No segundo ano experimental, as condições climáticas foram desfavoráveis para o desenvolvimento da cultura, principalmente, devido às temperaturas elevadas na fase final do processo de maturação (Figura 2), o que possibilitou maior ocorrência de sementes esverdeadas (Tabela 3) e aliada a elevada incidência da doença ferrugem asiática nos tratamentos 1 e 2, também, pode ter contribuído para a elevada porcentagem de sementes esverdeadas (Tabela 3 ). $\mathrm{O}$ tratamento testemunha apresentou pior desempenho em relação à produtividade e massa de matéria seca, seguido do tratamento 2 , em valores absolutos. A baixa eficiência de controle da doença pela mistura flutriafol + tiofanato metílico também foi constatada nos ensaios de campo realizados pela Embrapa Soja para avaliar a eficiência de fungicidas para o controle da ferrugem na safra 2008/09, sendo constatada, além da baixa eficiência no controle da doença, interferência negativa na produtividade (Godoy et al, 2009).
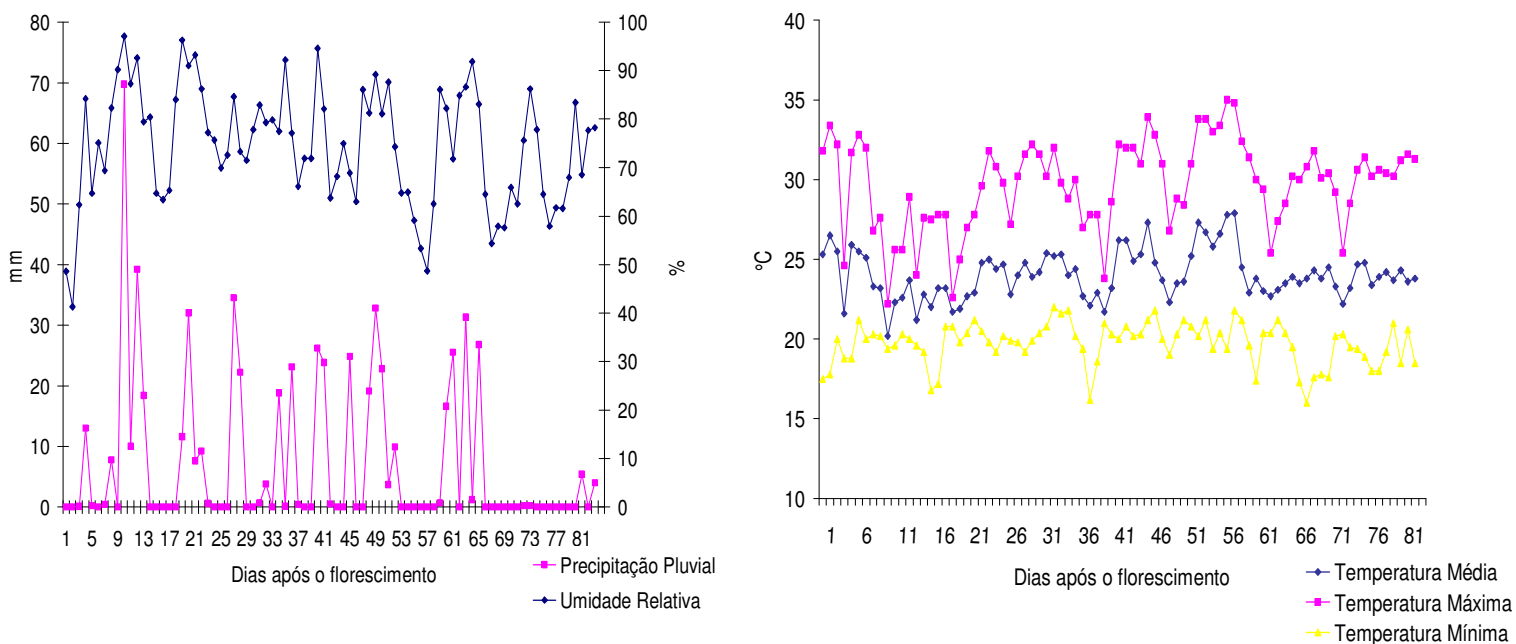

FIGURA 2. Dados meteorológicos de Londrina-PR, coletados do dia 5 de janeiro de 2009 a 18 de março de 2009. 
Apesar da elevada ocorrência de sementes esverdeadas, na primeira época de avaliação não houve interferência destas na qualidade das sementes, evidenciado pelos testes de germinação, envelhecimento acelerado e tetrazólio (Tabela 4). Apenas a condutividade elétrica diferenciou os tratamentos, apontando o tratamento 1 como de pior qualidade, não diferindo do tratamento 2. A menor integridade das membranas das sementes que degradaram parcialmente a clorofila pode ter sido constatada por este teste (Zorato et al., 2007).

TABELA 3. Médias de severidade de ferrugem asiática (SFA), ocorrência de sementes esverdeadas (OSV), produtividade $(P)$ e massa de mil sementes $\left(M_{1000}\right)$, cultivar CD 206, safra 2008/2009.

\begin{tabular}{|c|c|c|c|c|}
\hline \multirow{2}{*}{ Trat. } & SFA & OSV & $\mathrm{P}$ & $\mathrm{M}_{1000}$ \\
\hline & \multicolumn{2}{|c|}{$\%$} & $\mathrm{~kg} \cdot \mathrm{ha}^{-1}$ & $\mathrm{G}$ \\
\hline 1 & $59 \mathrm{a}$ & $40 \mathrm{a}$ & $490 \mathrm{~b}$ & $75 \mathrm{~b}$ \\
\hline 2 & $23 \mathrm{ab}$ & $31 \mathrm{ab}$ & $749 \mathrm{ab}$ & $78 a b$ \\
\hline 3 & $5 \mathrm{~b}$ & $20 \mathrm{ab}$ & $1384 \mathrm{a}$ & $82 a b$ \\
\hline 4 & $3 \mathrm{~b}$ & $13 \mathrm{~b}$ & $1330 \mathrm{a}$ & $80 a b$ \\
\hline 5 & $4 \mathrm{~b}$ & $21 \mathrm{ab}$ & $1443 \mathrm{a}$ & $81 \mathrm{ab}$ \\
\hline 6 & $4 \mathrm{~b}$ & $17 \mathrm{~b}$ & $1354 \mathrm{a}$ & $80 a b$ \\
\hline 7 & $6 \mathrm{~b}$ & $14 \mathrm{~b}$ & $1300 \mathrm{a}$ & $83 a$ \\
\hline $\mathrm{CV}(\%)$ & 109,9 & 25,07 & 25,93 & 4,42 \\
\hline
\end{tabular}

Médias seguidas por letras diferentes na coluna diferem entre si pelo teste de Tukey aos $5 \%$ de probabilidade

TABELA 4. Resultados de teor de água (TA), germinação (G), envelhecimento acelerado (EA), condutividade elétrica $(\mathrm{CE})$, tetrazólio $(\mathrm{TZ})$ vigor $(\mathrm{Vi})$ e viabilidade $(\mathrm{Vb})$, referentes a primeira e a segunda épocas de avaliação e resultados de fluorescência de clorofila na segunda época de avaliação, cultivar CD 206, safra 2008/2009.

\begin{tabular}{|c|c|c|c|c|c|c|c|c|c|c|c|c|c|}
\hline \multirow{4}{*}{$\mathrm{T}$} & \multicolumn{6}{|c|}{ Primeira época de avaliação } & \multicolumn{7}{|c|}{ Segunda época de avaliação } \\
\hline & \multirow{3}{*}{ TA } & \multirow{2}{*}{ G } & \multirow{2}{*}{ EA } & \multirow{2}{*}{$\mathrm{CE}$} & \multicolumn{2}{|c|}{$\mathrm{TZ}$} & \multirow{2}{*}{ TA } & \multirow{2}{*}{ Germ } & \multirow{2}{*}{ EA } & \multirow{2}{*}{$\mathrm{CE}$} & \multicolumn{2}{|c|}{$\mathrm{TZ}$} & \multirow{2}{*}{$\mathrm{FC}$} \\
\hline & & & & & $\mathrm{Vi}$ & $\mathrm{Vb}$ & & & & & $\mathrm{Vi}$ & $\mathrm{Vb}$ & \\
\hline & & $\%$ & & $\mu \mathrm{S} . \mathrm{cm}^{-1} \cdot \mathrm{g}^{-1}$ & \multicolumn{2}{|c|}{$\%$} & & $\%$ & & $\mu \mathrm{S} . \mathrm{cm}^{-1} \cdot \mathrm{g}^{-1}$ & \multicolumn{2}{|c|}{$\%$} & $\mathrm{pA}$ \\
\hline 1 & 8,0 & $92 \mathrm{a}$ & $87 \mathrm{a}$ & $131,3 \mathrm{a}$ & $78 \mathrm{a}$ & $88 \mathrm{a}$ & 11,5 & $83 \mathrm{a}$ & $46 \mathrm{~d}$ & $174,7 \mathrm{a}$ & $88 \mathrm{~b}$ & $77 \mathrm{c}$ & $1384 \mathrm{a}$ \\
\hline 2 & 8,5 & $92 \mathrm{a}$ & $88 \mathrm{a}$ & $120,1 \mathrm{ab}$ & $81 \mathrm{a}$ & $91 \mathrm{a}$ & 11,3 & $89 \mathrm{a}$ & $65 \mathrm{c}$ & $139,5 \mathrm{a}$ & $91 \mathrm{ab}$ & $79 \mathrm{c}$ & $1163 \mathrm{ab}$ \\
\hline 3 & 8,6 & $94 \mathrm{a}$ & $91 \mathrm{a}$ & $91,0 \mathrm{~b}$ & $81 \mathrm{a}$ & $91 \mathrm{a}$ & 11,5 & $88 \mathrm{a}$ & $73 \mathrm{bc}$ & $118,7 \mathrm{bc}$ & $91 \mathrm{ab}$ & $81 \mathrm{bc}$ & $945 \mathrm{~b}$ \\
\hline 4 & 8,6 & $96 \mathrm{a}$ & $91 \mathrm{a}$ & $90,7 \mathrm{~b}$ & $87 \mathrm{a}$ & $94 \mathrm{a}$ & 11,5 & $93 \mathrm{a}$ & $77 \mathrm{ab}$ & $107,1 \mathrm{~cd}$ & $96 \mathrm{a}$ & $89 a$ & $850 \mathrm{~b}$ \\
\hline 5 & 8,5 & $95 \mathrm{a}$ & $83 \mathrm{a}$ & $91,7 \mathrm{~b}$ & $86 a$ & $92 \mathrm{a}$ & 11,4 & $92 \mathrm{a}$ & $75 \mathrm{ab}$ & $104,6 \mathrm{~cd}$ & $93 \mathrm{ab}$ & $88 \mathrm{ab}$ & $969 \mathrm{~b}$ \\
\hline 6 & 8,7 & $96 \mathrm{a}$ & $85 a$ & $100,3 \mathrm{~b}$ & $84 \mathrm{a}$ & $95 \mathrm{a}$ & 11,8 & $93 a$ & 85 a & $87,4 \mathrm{~d}$ & $95 \mathrm{a}$ & $86 a b c$ & $913 \mathrm{~b}$ \\
\hline 7 & 8,5 & $98 \mathrm{a}$ & $85 \mathrm{a}$ & $99,9 \mathrm{~b}$ & $78 \mathrm{a}$ & $92 \mathrm{a}$ & 11,5 & $94 \mathrm{a}$ & $85 \mathrm{a}$ & $96,4 \mathrm{~cd}$ & $95 \mathrm{a}$ & $85 a b c$ & $950 \mathrm{~b}$ \\
\hline V\% & - & 8,40 & 11,9 & 23,7 & 5,04 & 3,50 & - & 5,26 & 6,40 & 9,33 & 3,82 & 4,49 & 14,91 \\
\hline
\end{tabular}

Médias seguidas por letras diferentes na coluna diferem entre si pelo teste de Tukey aos $5 \%$ de probabilidade.

Após o armazenamento, a germinação das sementes permaneceu elevada, sem diferença entre os tratamentos, porém os testes de vigor evidenciaram a redução do potencial fisiológico, sendo as sementes do tratamento 
1 com pior desempenho seguido do tratamento 2, na maioria dos testes (Tabela 4). Assim, observa-se que os tratamentos que apresentaram maior porcentagem de sementes esverdeadas foram aqueles que tiveram o vigor reduzido após o armazenamento. De acordo com Zorato e Watanabe (2006) as sementes esverdeadas têm reduzido potencial de armazenamento, pois estas apresentam mudanças associadas ao processo de deterioração, responsáveis pela menor longevidade. No presente estudo, verificou-se que a presença de clorofila não degradada comprometeu o vigor das sementes após o armazenamento.

O teste de fluorescência de clorofila também identificou que o tratamento 1 apresentou maior conteúdo de clorofila, não diferindo do tratamento 2 (Tabela 4). Desta forma, os resultados deste teste corroboraram com os obtidos pelos testes de vigor e também com o da avaliação visual da porcentagem de sementes esverdeadas. Cícero et al. (2009) também constataram a eficiência do equipamento "CF Seed Sorter \& Analyser" para avaliação e separação de sementes esverdeadas em soja.

\section{CONCLUSÕES}

Os fungicidas foliares, que controlam de forma eficiente a doença ferrugem asiática, não interferem na produção, na qualidade das sementes e na ocorrência de sementes esverdeadas.

Em condições climáticas favoráveis à maturação das sementes, a alta severidade da doença ferrugem asiática interfere na produtividade, mas não influencia no seu potencial fisiológico.

A ferrugem asiática, associada às condições climáticas desfavoráveis na fase final de maturação, proporciona a ocorrência de sementes esverdeadas, que compromete o vigor das sementes após o armazenamento.

\section{AGRADECIMENTOS}

À FAPESP, pela bolsa concedida à primeira autora e aos pesquisadores Henk Jalink e Rob Van Der Schoor do "Plant Research International", Wageningen/Holanda, pelo auxílio na condução do teste de fluorescência de clorofila.

\section{REFERÊNCIAS}

BOHNER, H. Green Soybeans. Ministry of agriculture, food and rural affairs, Ontario, 2003. Disponível em: <http://www.omafra.gov.on.ca/english/crops/facts/ green beans02.htm $>$. Acesso em: 2 ago. 2010.

BRASIL. Ministério da Agricultura, Pecuária e Abastecimento. Regras para análise de sementes. Ministério da Agricultura, Pecuária e Abastecimento. Secretaria de Defesa Agropecuária. Brasília, DF: Mapa/ ACS, 2009. 395p.

CICERO, S.M.; van der SCHOOR, ROB.; JALINK, H. Using chlorophyll fluorescence sorting to improve seed lot quality in soybean. Revista Brasileira de Sementes, v.31, n.4, p.145-151, 2009.

EMBRAPA SOJA. Tecnologia de produção de soja - Região Central do Brasil 2009 e 2010. Londrina: EMBRAPA Soja, 2008. p.196-201. (Sistemas de Produção, 13).

FEHR, W.R.; CAVINESS, C.E.; BURMOOD, D.T.; PENNINGTON, J.S. Stage of development description for soybeans (Glycine max (L.) Merrill). Crop Science, v.11, n.6, p.929-931, 1971.

FRANÇA NETO, J.B.; KRZYZANOWSKI, F.C.; COSTA, N.P. Metodologia do teste de tetrazólio de sementes de soja. In: KRZYZANOWSKI, F.C.; VIEIRA, R.D.; FRANÇA NETO, J.B. (Ed.) Vigor em sementes: conceitos e testes. Londrina: ABRATES, 1999. Cap.8, p.1-28.

GODOY, C.V.; PIMENTA, C.B.; MIGUEL-WRUCK, D.S.; RAMOS JUNIOR, E.U.; SIQUERI, F.V.; FEKSA, H.R.; DOS SANTOS, I.; LOPES, I.O.N.; NUNES JUNIOR, J.; ITO, M.A.; IAMAMOTO, M.M.; ITO, M.F.; MEYER, M.C.; DIAS, M.; MARTINS, M.C.; ALMEIDA, N.S.; ANDRADE, N.S.; ANDRADE, P.J.M.; SOUZA, P.I.M.; BALARDIN, R.S.; BARROS, R.; SILVA, S.A.; FURLAN, S.H.; GAVASSONI, W.L. Eficiência de fungicidas para controle da ferrugem asiática da soja, Phakopsora pachyrhizi, na safra 2008/09. Resultados sumarizados dos ensaios cooperativos. Londrina: EMBRAPA Soja, 2009. 11p. (Circular Técnica, 69).

JACCOUND FILHO, D.S.; HIAR, C.P.; BONA, P.F.; GASPERINI, L. Ocorrência da ferrugem da soja na região dos Campos Gerais do Paraná. In: REUNIAO DE PESQUISA DE SOJA DA REGIAO CENTRAL DO BRASIL, 23, Londrina, 2001. Resumos... Londrina, 2001. p.109.

MARCOS FILHO, J. Teste de envelhecimento acelerado. In: KRZYZANOWSKI, F.C.; VIEIRA, R.D.; FRANÇA NETO, J.B. Vigor de sementes: conceitos e testes. Londrina: ABRATES, Comitê de Vigor de Sementes, 1999. cap. 3, p.1-24. 
PÁDUA, G.P. FRANÇA NETO, J.B; CARVALHO, M. L. M; KRYZANOWSKI, F. C; GUIMARÃES, R. $M$. Incidence of grem soybean seeds as a function of environmental stress during seed maturation. Revista Brasileira de Sementes, v.31, n.3, p.150-159, 2009.

SAS INSTITUTE. SAS/STAT user's guide: SAS onlineDoc: version 8.2 Cary, 2000. CD- Rom.

SINCLAIR, J.B.; BACKMAN, P.A. (Ed.). Compendium of soybean diseases. $3^{\text {rd }}$ St. Paul: American Phytopathological Society, 1989. p.24-27.

SINCLAIR, J.B.; HARTMAN, G.L. Soybean Rust. In: HARTMAN, G.L.; SINCLAIR, J.B.; RUPE, J.C. (Ed.). Compendium of soybean diseases. 4. ed. St. Paul: American Phytopathological Society. 1999. p.25-26.

SWOBODA, C.; PEDERSEN, P. Effect of fungicide on soybean growth and yield. Agronomy Journal. v.10, n.2, p.352-356, 2009.

VIEIRA, R.D.; KRZYZANOWSKI, F.C. Teste de condutividade elétrica. In: KRZYZANOWSKI, F.C.; VIEIRA, R.D.; FRANÇA NETO, J.B. (Ed.). Vigor de sementes: conceitos e testes. Londrina: ABRATES, 1999. Cap.4, p.1-26.

WARD, K.; SCARTH, R.; DAUN, J.K.; VESSEY, J.K. Chlorophyll degradation in summer oilseed rape and summer turnip rape during seed ripening. Canadian Journal of Plant Science, v.75, n.2, p. 413-420, 1995.

WIEBOLD, B. Soybean plants killed before maturity possess grain that remains green. Missouri, 2000. Disponível em: <http://www.psu.missouri.edu/soyx/ soyfacts/green.PDF>. Acesso em: 1 nov. 2010.

YANG, X.B.; TSCHANZ, A.T.; DOWLER, W.M.; WANG, T.C. Development of yield loss models in relation to reductions of components of soybean infected with Phakopsora pachyrhizi. Jourmal of Phytopathology, v.81, n.11, p.1420-1426, 1991.

YORINORI, J.T.; YORINORI, M.A.; GODOY, C.V. Seleção de cultivares de soja resistentes à ferrugem "asiática" (Phakopsora pachyrhizi). In: REUNIÃO SUL DE SOJA DA REGIÃO SUL, 30., 2002, Cuz Alta. Atas e Resumos... 2002. Cruz Alta: FUNDACEP FECOTRIGO, 2002. p.94.

ZORATO, M.F.; PESKE, S.T.; TAKEDA, C.; FRANÇA NETO, J.B. Presença de sementes esverdeadas em soja e seus efeitos sobre seu potencial fisiológico. Revista Brasileira de Sementes. v.29, n.1, p.11-19, 2007.

ZORATO, M.F.; WATANABE, P.A.T. Soja esverdeada: a degradação parcial da clorofila. In: SUZUKI, S.; YUYAMA, M.M.; CAMACHO, S.A. Boletim de Pesquisa de Soja 2006. Rondonópolis: Fundação MT, 2006. p.229-232. 